\title{
Evaluation of an ear-tag-based accelerometer for monitoring rumination in dairy cows
}

\author{
S. Reiter, ${ }^{*}$ G. Sattlecker,† L. Lidauer,† F. Kickinger,† M. Öhlschuster,† W. Auer,† V. Schweinzer, ${ }^{*}$ \\ D. Klein-Jöbstl, ${ }^{*}$ M. Drillich, ${ }^{*}$ and M. Iwersen*1 \\ ${ }^{*}$ Clinical Unit for Herd Health Management in Ruminants, University Clinic for Ruminants, Department for Farm Animals \\ and Veterinary Public Health, University of Veterinary Medicine Vienna, 1210 Vienna, Austria \\ †Smartbow GmbH, Jutogasse 3, 4675 Weibern, Austria
}

\section{ABSTRACT}

The objective of this study was to evaluate the eartag-based accelerometer system Smartbow (Smartbow GmbH, Weibern, Austria) for detecting rumination time, chewing cycles, and rumination bouts in indoorhoused dairy cows. For this, the parameters were determined by analyses of video recordings as reference and compared with the results of the accelerometer system. Additionally, we tested the intra- and interobserver reliability as well as the agreement of direct cow observations and video recordings. Ten Simmental dairy cows in early lactation were equipped with 10$\mathrm{Hz}$ accelerometer ear tags and kept in a pen separated from herd mates. A total mixed ration was fed twice a day via a roughage intake control system. During the study, cows' rumination and other activities were directly observed for $20 \mathrm{~h}$ by 2 trained observers. Additionally, cows were video recorded for $19 \mathrm{~d}, 24 \mathrm{~h}$ a day. After exclusion of unsuitable videos, $2,490 \mathrm{~h}$ of cow individual 1-h video sequences were eligible for further analyses. Out of this, one hundred 1-h video sequences were randomly selected and visually and manually classified by a trained observer using professional video analyses software. Based on these analyses, half of the data was used for development (based on data of 50-h video analyses) and testing (based on data of additional 50-h video analyses) of the Smartbow algorithms, respectively. Inter- and intra-observer reliability as well as the comparison of direct against video observations revealed in high agreements for rumination time and chewing cycles with Pearson correlation coefficients $>0.99$. The rumination time, chewing cycles, as well as rumination bouts detected by Smartbow were highly associated $(r>0.99)$ with the analyses of video recordings. Algorithm testing revealed in an underestimation of the average \pm standard deviation rumination time

Received February 4, 2017.

Accepted December 2, 2017.

${ }^{1}$ Corresponding author: Michael.Iwersen@vetmeduni.ac.at per 1-h period by the Smartbow system of $17.0 \pm 35.3$ s (i.e., $-1.2 \%$ ), compared with visual observations. The average number \pm standard deviation of chewing cycles and rumination bouts was overestimated by Smartbow by $59.8 \pm 79.6$ (i.e., $3.7 \%$ ) and by $0.5 \pm 0.9$ (i.e., $1.6 \%$ ), respectively, compared with the video analyses. In summary, the agreement between the Smartbow system with video analyses was excellent. From a practical and clinical point of view, the detected differences were negligible. However, further research is necessary to test the system under various field conditions and to evaluate the benefit of incorporating rumination data into herd management decisions.

Key words: cow, accelerometer, rumination, monitoring

\section{INTRODUCTION}

Rumination is essential in the digestive physiology of ruminants. It can be defined as a process characterized by regurgitation, mastication, and re-swallowing of ingesta (Beauchemin, 1991). The number of chews per bolus is associated with the fiber content of the feed, but in general rumination activity can be influenced by several environmental factors, such as the nature and amount of feed (Metz, 1975; Suzuki et al., 2014) or milking schedules and patterns of lighting (Beauchemin, 1991). Adult cows ruminate approximately $8 \mathrm{~h}$ per day in 4 to 24 periods, each lasting 10 to $60 \mathrm{~min}$ (Gáspárdy et al., 2014). Nevertheless, rumination time seems to have a physiological limit of approximately 10 $\mathrm{h}$ per day, but rumination times of $12 \mathrm{~h}$ per day have also been reported (Welch, 1982; Beauchemin, 1991; Liboreiro et al., 2015).

An inhibition of rumination activity can be caused by low $\mathrm{pH}$ or high osmotic pressure in the rumen (Welch, 1982). Focant et al. (1979) detected reduced rumination activity in association with VFA concentrations in the ruminal fluid in goats.

A decrease of rumination activity is also reported to be an indicator of stress (Herskin et al., 2004). Consid- 
ering these physiological factors, sensor-based continuous monitoring of rumination activity has the potential to be used for herd health management decisions. For instance, the association between rumination activity and ruminal $\mathrm{pH}$ (Welch, 1982) provides the opportunity for an early detection of cows suffering from rumen acidosis. Recently, Stangaferro et al. (2016a,b,c) evaluated the monitoring of rumination and activity for identification of cows with health disorders. For nondiseased animals, the authors reported an average rumination time of approximately $500 \mathrm{~min}$ per d. For cows that developed metabolic disorders, digestive disorders, or both, the rumination time was lower $(P \leq 0.05)$ from -5 to $5 \mathrm{~d}$ relative to the clinical diagnosis (d 0 ) with a nadir of approximately $262 \mathrm{~min}$ per $\mathrm{d}$ on $\mathrm{d} 0$.

Liboreiro et al. (2015) reported the days relative to calving, stillbirth, subclinical hypocalcemia, and retained fetal membranes as the most important factors associated with the daily rumination time during the prepartum period. Postpartum, the most important factors associated with the daily rumination time were the days relative to calving, twinning, subclinical hypocalcemia, subclinical ketosis, and retained fetal membranes.

A health index score (HIS) based on rumination and activity data determined by the Hi-Tag rumination monitoring system (SCR Engineers Ltd., Netanya, Israel) was recently evaluated by Stangaferro et al. (2016a,b,c). The HIS showed high sensitivities of 98, 91, and $89 \%$ in detecting animals suffering from displaced abomasum, ketosis, and indigestion, respectively, that were detected 0.5 to $3 \mathrm{~d}$ before the clinical diagnosis by farm personnel. The reported sensitivities of HIS in detecting clinical mastitis and metritis were $58 \%$ ( $81 \%$ for mastitis caused by Escherichia coli) and $55 \%$, respectively. Hence, the authors concluded that monitoring rumination time and physical activity could be useful for identifying cows with metabolic and digestive disorders in the early postpartum period. Additionally, the automated rumination and monitoring system was reported to be effective for identifying cows suffering from mastitis caused by E. coli as well as for cows suffering from severe metritis.

As rumination activity is reported to decrease during estrus (Reith and Hoy, 2012) and parturition (Pahl et al., 2014; Clark et al., 2015), this parameter might be useful for detecting cows in estrus or in predicting parturition.

Visual observation of rumination activity is regarded as a reliable method and considered as the gold standard, but is labor intensive (Schirmann et al., 2009; Burfeind et al., 2011). Some devices for monitoring rumination, for instance the Hi-Tag rumination moni- toring system (SCR Engineers Ltd.) and Qwes-HR (Lely Ltd., St. Neots, UK), record mastication sounds (Beauchemin et al., 1989; Schirmann et al., 2009; Burfeind et al., 2011; Goldhawk et al., 2013; AmbrizVilchis et al., 2015), whereas others, for instance the IGER Behavior Recorder systems (Ultra Sound Advice, London, UK), measure jaw movements (Kononoff et al., 2002; Umemura et al., 2009). Another system, the CowManager SensOor (Agis Automatisering BV, Harmelen, the Netherlands) consists of an ear-tagged device (Bikker et al., 2014; Borchers et al., 2016). Similar to this system, the Smartbow ear tag (Smartbow GmbH, Weibern, Austria) used in this study consists of an acceleration sensor to recognize rumination activity, among others. Furthermore, the location as well as the locomotion activity of a cow can be detected (Wolfger et al., 2017).

The primary objective of this study was to evaluate the suitability of the Smartbow system for monitoring rumination activity by comparison of the recorded rumination time, jaw movements, and rumination bouts with video observations, performed by a trained observer. Additional objectives were to test the intra- and inter-observer reliability as well as the agreement of direct animal observations and video recordings.

\section{MATERIALS AND METHODS}

All study procedures were discussed and approved by the institutional ethics and welfare committee in accordance with Good Scientific Practice guidelines and national legislation (ETK-05/07/15). The study was conducted from June to August 2015 at the Teaching and Research Farm of the University of Veterinary Medicine, Vienna (Austria), keeping approximately 75 Simmental dairy cows in a freestall barn. The cows were milked twice daily in a tandem milking parlor. The average ECM yield (based on $4.0 \%$ butterfat and $3.4 \%$ protein) of the herd in 2016 was $8,755 \mathrm{~kg}$ per cow.

\section{Animals and Housing}

Ten clinically healthy cows were selected from the herd. These cows were housed together in a pen (Figure 1) separated from the other herd mates for the duration of the study (i.e., during visual and video observations and data recording by accelerometers). Cows were enrolled in the study at the same time independent of lactation number (median lactation number: 2; minimum: 1; maximum: 8) and in peak lactation (mean DIM \pm SD: $73 \pm 27 \mathrm{~d}$ ). Each of the 10 cows was equipped with one Smartbow ear tag device. Every cow 


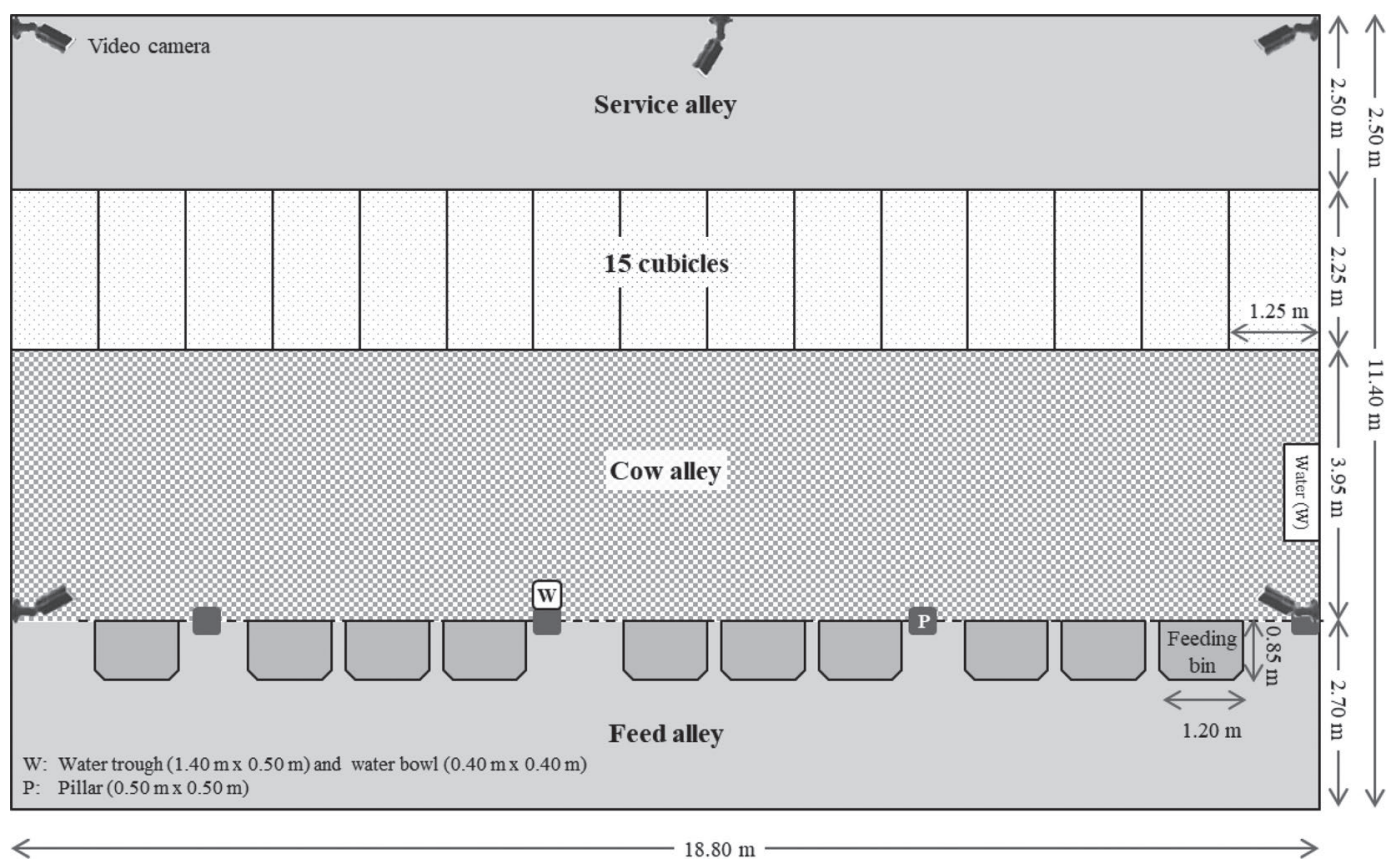

Figure 1. Pen layout and positioning of video cameras.

had at least 1 wk to habituate to the ear tag and the study settings before the study started. For a reliable identification during observations, cows were marked with an individual number ranging from 1 to 10 on each side of the croup. Standard operating procedures that were already implemented on farm were used for checking the animals for health disorders (i.e., at least 2 times a day during milkings) as well as for estrus detection (i.e., at least 3 times a day). During the study period, no health disorders were detected. Two animals in estrus were observed, but data were not excluded from statistical analyses.

The pen was equipped with 15 cubicles with compact straw-mattresses, top dressed with fresh straw every day. All cows had unlimited access to 10 computer-controlled automatic roughage feeders (Insentec Roughage Intake Control System, Hokofarm Group B.V., Marknesse, the Netherlands), which were filled twice a day at 0730 and $1800 \mathrm{~h}$ with a TMR consisting of grass silage, corn silage, grass hay, and 2 concentrate mixtures (Table 1). The ration was mixed by an automatic feeding system (Trioliet T10, Trioliet B.V., Oldenzaal, the Netherlands). Water was offered ad libitum by a water trough and water bowl, and cows had access to a salt lick stone. Approximately 2 mo after enrollment, a TMR with a differing roughage composition (Table 1) was fed using the identical cows (mean DIM \pm SD: $133 \pm 27 \mathrm{~d}$ ). This had the advantage that cows did not need to habituate to the pen and electronic feeders,
Table 1. Summary of formulated feed ingredient amounts, analyzed nutrients of the TMR, and results of a Penn State Particle-SizeSeparator test

\begin{tabular}{|c|c|c|}
\hline \multirow[b]{2}{*}{ Feed ingredient or nutrient } & \multicolumn{2}{|c|}{$\begin{array}{l}\text { TMR fed } \\
\text { in study period }\end{array}$} \\
\hline & 1 & 2 \\
\hline $\mathrm{DM}(\%)$ & 46.8 & 45.0 \\
\hline \multicolumn{3}{|l|}{ Ingredient ( $\%$ of DM) } \\
\hline Grass silage & 26.9 & 58.0 \\
\hline Corn silage with alfalfa & 31.1 & - \\
\hline Grass hay & 1.9 & 1.9 \\
\hline Concentrate $\operatorname{mix}^{1}$ & 30.6 & 30.6 \\
\hline High protein concentrate $^{2}$ & 9.6 & 9.6 \\
\hline \multicolumn{3}{|l|}{ Nutrient (g per kg of DM) } \\
\hline $\mathrm{CP}$ & 155 & 142 \\
\hline Crude fat & 25 & 24 \\
\hline Crude fiber & 199 & 226 \\
\hline NDF & 343 & 398 \\
\hline Cellulose and lignin & 267 & 291 \\
\hline Lignin & 42 & 37 \\
\hline NFC & 398 & 355 \\
\hline Nitrogen-free extractives & 542 & 527 \\
\hline Crude ash & 79 & 80 \\
\hline ME (MJ) & 10.94 & 10.72 \\
\hline & 6.64 & 6.49 \\
\hline \multicolumn{3}{|c|}{ Distribution of particle size fractions ${ }^{3}(\%)$} \\
\hline Upper sieve & 67 & 83 \\
\hline Lower sieve & 5 & 5 \\
\hline Bottom pan & 28 & 12 \\
\hline
\end{tabular}

${ }^{1}$ Concentrate mix consisting of grain corn, wheat, rye, and minerals.

${ }^{2}$ High protein concentrate consisting of rapeseed meal, distillers grain, and sunflower concentrate.

${ }^{3}$ Pore sizes of Penn State Particle Size Separator: upper sieve $=19$ $\mathrm{mm}$, lower sieve $=8 \mathrm{~mm}$. 
and rumination data of cows fed a differing ration in an advanced lactation period could be used.

\section{Study Design}

The study design is illustrated in Figure 2. In the first part of the study (part 1), data were recorded for developing the algorithms for detecting rumination using the Smartbow system. For this, half of the data (i.e., from fifty 1-h video sequences) from video recordings was communicated to the manufacturer. In the second part of the study (part 2), starting approximately 2 mo after start of part 1 , the algorithm was tested on the other half of the analyzed data set. For this, the accelerometer data set was blinded and the manufacturer was asked to communicate to the authors of this manuscript the rumination data of a specific cow in a specific timeframe predicted by using the accelerometer data.

\section{Smartbow System and Data Collection}

The Smartbow ear tag consists of an integrated accelerometer. Commercially available ear tags capture acceleration data once per second $(1 \mathrm{~Hz})$, but in this study, ear tags capturing and sending data with a frequency of $10 \mathrm{~Hz}$ were used. Data were sent in real time via a receiver device (Smartbow Wallpoint) to a local server (Smartbow Station). Acceleration data are processed by the Smartbow Station by using programmed algorithms to detect cow activities, for instance, estrus and rumination. Rumination data (i.e., the minutes an animal spent ruminating per hour and day) are presented visually on a local computer (desktop client) or on a mobile device (mobile client).

Five cameras with integrated infrared illuminators [IR Bullet Network Camera Version DS-2CD2632F$\mathrm{I}(\mathrm{S})$, Hikvision, Hangzhou, China] were positioned

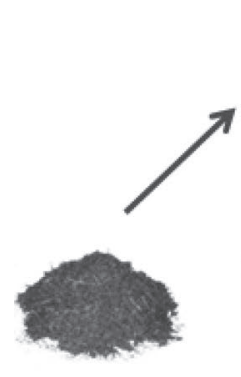

Feed ration 1

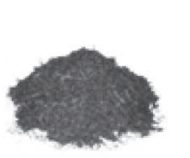

Feed ration 2

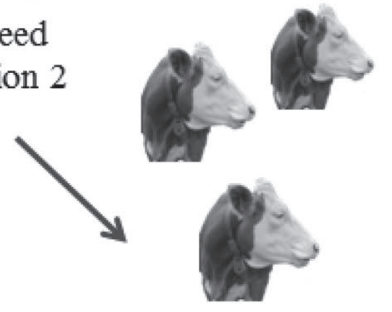

Rumination of 10 Simmental cows
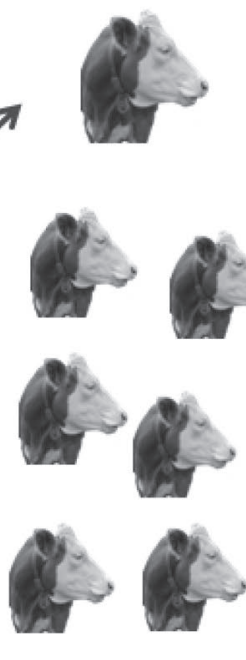

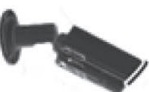

Permanent video recording
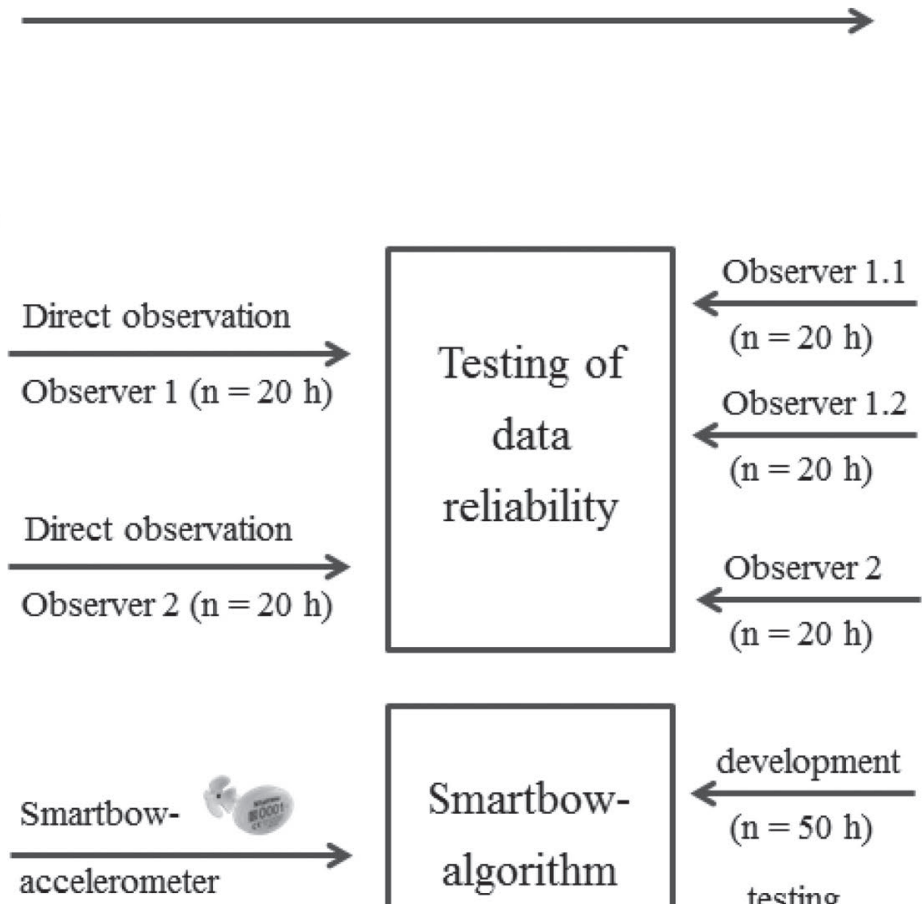

accelerometer

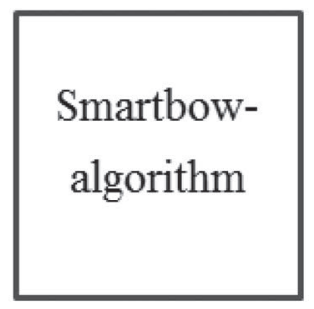

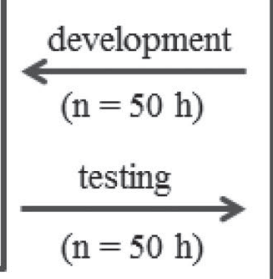

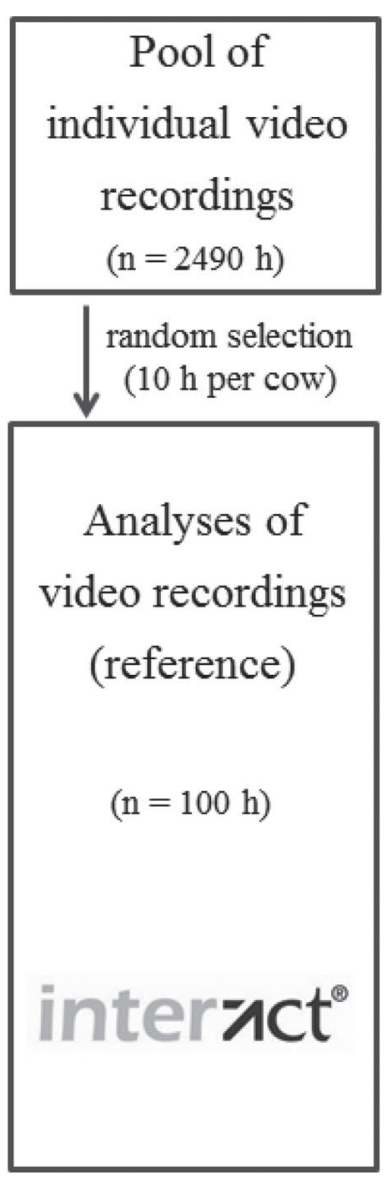

Figure 2. Study design. Two different rations were offered in consecutive trials (part 1 and part 2 of this study) to 10 Simmental cows. Rumination was observed by permanent video recording, direct observation by 2 independent observers, as well as by a 3-dimensional accelerometer (Smartbow, Smartbow GmbH, Weibern, Austria). Out of the pool of individual video recordings, $10 \mathrm{~h}$ per cow (i.e., $100 \mathrm{~h}$ in total) was randomly selected for further analyses by using video analysis software (Mangold Interact, Mangold International GmbH, Arnstorf, Germany). Data reliability was tested for direct observations (i.e., inter-observer reliability) and video analyses (i.e., inter- and intra-observer reliability). Half of the data of the video analyses was used for the development of the Smartbow algorithm for detecting rumination activity. The other half of the data was used for a blind validation of the developed algorithm. 
throughout the pen (Figure 1) at a height of approximately $4 \mathrm{~m}$. Three cameras were mounted in front of the cubicles, and 2 additional cameras were directed at the loafing area and at the feeding bins. Cameras recorded $24 \mathrm{~h}$ per day. With fading daylight, cameras automatically switched to infrared mode to ensure a continuous observation during night times.

Except for the milking times, cows were housed in the pen for the duration of the study. For the milking process, cows left the pen for approximately $1 \mathrm{~h}$ in the morning $(0630 \mathrm{~h})$ and $1.5 \mathrm{~h}$ in the afternoon (1630 h). During these times cows were not monitored by direct or video observation. Every cow was identified by its unique number and the rumination process was recognizable in most situations. In preparation of this study, 2 observers were trained for direct and video observations. For this, both observers inspected various ruminating cows together for approximately $3 \mathrm{~h}$, until the recorded results matched adequately. Cow specific activities (Table 2) were pre-defined to provide a clear definition for various events needed for capturing the activities during the 1-h observation periods. For direct observation, activities were classified into categories (i.e., eating, drinking, ruminating) as shown in the ethogram. Activities seen in the video recordings were classified into main activities (i.e., lying, standing, walking) and optional activities (i.e., eating, drinking, ruminating, licking/scratching). The onset of rumination was defined as the time point when a bolus reached the mouth after regurgitation. The end time was defined as the moment of re-swallowing the bolus (Schirmann et al., 2009). The process from regurgitating until re-swallowing the cud was defined as one "rumination bout."

Observers recorded the start and end point of every rumination bout and counted the number of chewing cycles per bolus (defined as a complete course of movement of the mandible during a single masticatory stroke). The first closure of the mouth, followed by swallowing fluid coming out of the compressed bolus, was defined as the first chewing cycle.

During direct animal observation, observers independently watched each of the 10 cows for two 1-h periods, simultaneously. For this, observers were standing in front of the cubicles, where cow activities of a specific animal could be recorded easily, without excessively influencing the cows' behaviors. The observers did not communicate with each other and were unable to see the others recordings during the observation periods. Within an 1-h observation period the activities of only 1 cow were monitored. Recorded activities were directly entered on tablet devices (E-Board MX049, Proworx, S\&T AG, Linz, Austria) using a self-programmed Microsoft Excel application (Excel 2015, Microsoft Corporation, Redmond, WA). Activities recorded in this manner were documented in an Excel spreadsheet with a unique time signature (as hh:mm:ss:ms). For a reliable comparison of the recorded activities, the system times of the tablet devices, the camera network, and the Smartbow system were synchronized at $0000 \mathrm{~h}$ each day with a Windows time server (Windows Server 2012 R2, Microsoft Corporation).

During the study, cows were video recorded for 19 days in total (part 1: $8 \mathrm{~d}$, part 2: $11 \mathrm{~d}$ ), approximately $21.5 \mathrm{~h}$ a day (no recordings during milking). Because of problems in recognizing some cows on videos during night times in part 1 , only recordings during daytimes (0800 to $1600 \mathrm{~h}$ ) were used for analyses for this part. Excluding the additional video sequences when cows were absent for milking, 570 one-hour cow individual video recordings for part 1 and 1,920 onehour recordings for part 2 were eligible for analyses. Out of this entire pool of video recordings (i.e., 2,490 h), 10 observation periods of $1 \mathrm{~h}$ each per cow (i.e., $100 \mathrm{~h}$ in total) were chosen by using a random generator (BiAS, Version 9.07, Epsilon-Verlag, Darmstadt, Germany) for further classification with professional software for video analyses (Mangold Interact, Mangold Interna-

Table 2. Classification of activities for direct visual observation and analysis of video recordings

\begin{tabular}{|c|c|}
\hline Item & Definition \\
\hline Lying $^{1}$ & Cow is lying, carpal and tarsal joints are on the ground \\
\hline Standing ${ }^{1}$ & Carpal or tarsal joints are not on the ground \\
\hline \multicolumn{2}{|l|}{ Optional activity } \\
\hline Eating ${ }^{1,2}$ & Feeding gate opened and cow head in or over the trough \\
\hline Drinking ${ }^{1,2}$ & Cow muzzle underwater in the bowl \\
\hline
\end{tabular}


tional GmbH, Arnstorf, Germany). With this software, videos were manually coded by a trained observer, pressing an activity-specific button on the keyboard as soon as an activity was observed as defined in Table 2 . With this procedure, coded activities were labeled with a unique time signature, enabling the comparison of these activities with data observed during direct visual observations as well as with the data generated by the Smartbow system.

In part 1 and 2, cows were directly observed by both observers for $10 \mathrm{~h}$ (resulting in $20 \mathrm{~h}$ per observer in total), at first. For comparison of direct observations with the video recordings, the twenty 1 -h video periods that matched exactly the hours of direct observations were analyzed by the principal author (observer 1) with the Mangold Interact software. To evaluate the interobserver reliability, the identical video sequences were analyzed by the second observer as well, and direct observation results of both observers were compared with each other as well as with video recordings (Figure 2).

\section{Statistical Analyses}

All data were captured in Microsoft Excel spreadsheets. For further analyses, the statistical software package SPSS (version 24, IBM Corporation, Armonk, NY) was used. The rumination time, chewing cycles and rumination bouts which were aggregated per $1 \mathrm{~h}$ of observations and stratified for part 1 and 2 of the study were tested for normal distribution (KolmogorovSmirnov test) and homogeneity of variance (Levene test). Pearson correlation coefficients were calculated and paired $t$-tests for rumination time, chewing cycles and rumination bouts (aggregated per $1 \mathrm{~h}$ of observations) were performed to test the association between the results obtained from the Smartbow system and video analyses as well as for inter- and intra-observer comparisons. Statistical significance for all tests was defined as $P<0.05$. Averages are reported as mean \pm standard deviation in the manuscript.

To test the intra-observer reliability, $20 \%$ of the analyzed video recordings (i.e., twenty 1 -h periods) were re-evaluated by observer 1 . To test the inter-observer reliability, results from direct observation from both observers were compared, and additionally, the second observer analyzed $20 \mathrm{~h}$ of video recordings as well to compare them with the results of observer 1.

Pearson correlation coefficients were calculated for rumination time and the number of chewing cycles per bolus determined by the 2 observers (inter-observer reliability), for the twice-analyzed periods (intra-observer reliability) as well as for the association between directly observed rumination activity and the results of video analyses. For the comparison of Smartbow against direct observations, the correlations between detected rumination bouts were calculated. Additionally, Pearson correlation coefficients for the rumination time, chewing cycles and rumination bouts estimated by Smartbow were calculated. For graphical illustration, the association between measurements of the Smartbow system and the results of the video analyses were depicted as described by Bland and Altman (1986) as well as by using boxplots (Figures 3, 4, 5, 6, 7, and 8).

Statistical analyses were performed separately for part 1 (algorithm development) and part 2 (algorithm testing) of the study to detect possible differences in the calculated parameters between both parts, and thereby testing for possible confounders.

\section{RESULTS}

The average DMI per cow and day recorded by the roughage intake control system was $19.6 \pm 2.4 \mathrm{~kg}$ (minimum: $16.2 \mathrm{~kg}$, maximum: $24.6 \mathrm{~kg}$ ) of TMR 1 in part 1 and $20.5 \pm 2.2 \mathrm{~kg}$ (minimum: $16.4 \mathrm{~kg}$, maximum: $23.4 \mathrm{~kg}$ ) of TMR 2 in part 2.

\section{Observer Reliability and Association Between Direct Observations and Video Analyses}

The results of the intra- and inter-observer reliability based on twenty 1-h observation periods of direct and video observations are presented in Table 3. All of the comparisons showed a near perfect agreement of $\mathrm{r}>$ $0.99(P<0.001)$.

The $t$-test resulted in a significant difference $(P<$ 0.01 ) of approximately 25 chewing cycles per h between observer 1 and observer 2 for the analyzed video sequences. A high agreement was found between the results of direct visual observations and the analyses of video recordings for rumination time and chewing cycles per hour $(\mathrm{r}=0.99, P<0.001$, for both).

\section{Rumination Time, Chewing Cycles, and Rumination Bouts Detected by Smartbow and Video Analyses}

Similar correlation coefficients of $\mathrm{r}>0.99(P<0.01)$ between the Smartbow system and the video analyses for rumination time were determined in part 1 and part 2 of the study (Table 4 ). The average rumination time of approximately $1,508 \pm 1,097 \mathrm{~s}$ per 1 -h period detected by visual observation was underestimated by Smartbow for $16 \pm 77 \mathrm{~s}(P=0.04$, Table 4; i.e., 1.1\%). The deviations between Smartbow and video observations against their mean are depicted as the BlandAltman plot in Figure 3. 


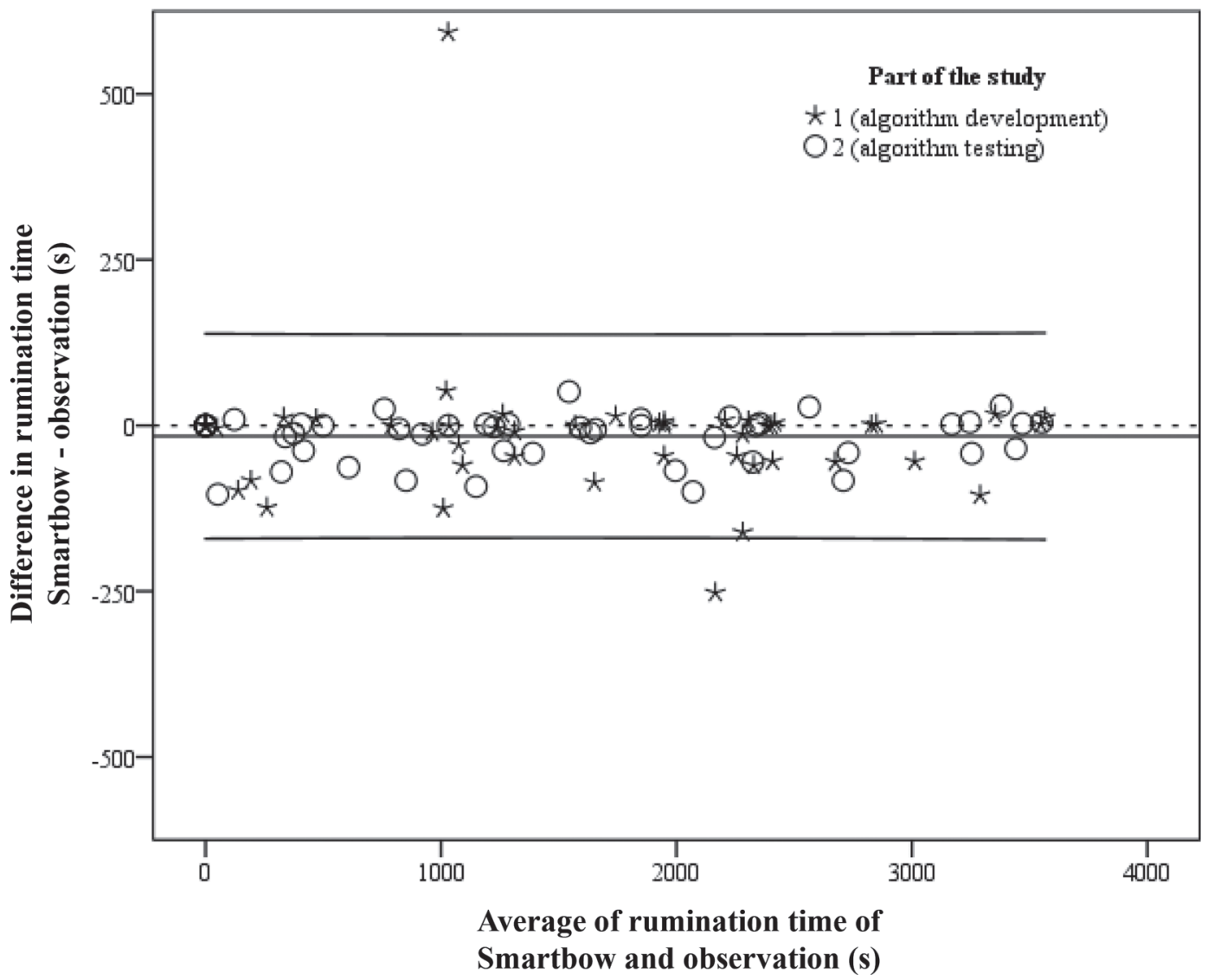

Figure 3. Differences between the rumination time (s) detected by Smartbow (Smartbow GmbH, Weibern, Austria) and by analyses of video observations against their mean. Data are shown for fifty 1-h periods, each for part 1 (algorithm development) and part 2 (algorithm testing) of the study. The upper and lower solid lines illustrate the mean $\pm 2 \mathrm{SD}$, and the solid line in the middle shows the mean. The dotted line indicates zero.

Visually observed chewing cycles were highly correlated $(\mathrm{r}>0.99, P<0.001)$ with the number of cycles recorded by Smartbow (Table 4). No differences of the correlation coefficients determined for part 1 and part 2 were observed. On average, Smartbow overestimated $(P<0.01)$ the number of chewing cycles by $61 \pm 98$ per 1-h period compared with the video observations (Table 4 and Figure 4), which corresponds to $3.7 \%$.

Observer 1 detected an average number of $29 \pm 21$ rumination bouts per cow in a 1-h period (Table 4). In comparison to the average number of observed rumination bouts, Smartbow slightly underestimated $(P$ $=0.046$, Table 4 ) the number by $0.4 \pm 1.9$ bouts (i.e., $-1.3 \%)$, resulting in a high correlation of $\mathrm{r}>0.99(P<$ 0.001 ) as presented in Table 4.

The 3 Bland-Altman plots (Figure 3, 4, and 5) indicate a high agreement between the analyses of video recordings and the Smartbow system for rumination time, chewing cycles, and rumination bouts, but 2 statistical outliers were identified within part 1 . In one 1-h period, the accelerometer detected an excessively high rumination time of $593 \mathrm{~s}(+80.9 \%)$ and additional 378 chewing cycles $(+47.1 \%)$. In a second 1-h period, the rumination activity detected by Smartbow was underestimated for $252 \mathrm{~s}(-11.0 \%)$ and 131 chewing cycles $(-4.9 \%)$ compared with video observations. The association between rumination time, chewing cycles, and rumination bouts determined by the Smartbow system revealed in correlation of $r>0.98(P<0.01$, for all comparisons).

Individual cow activities are shown as boxplots for rumination time, chewing cycles, and rumination bouts in Figures 6, 7, and 8.

\section{DISCUSSION}

Direct observation is often used as the gold standard for monitoring rumination activity in cows (Schirmann et al., 2009; Burfeind et al., 2011). For validation of the accelerometer, cows were monitored by video observation. To test the inter- and intra-observer reliability, 


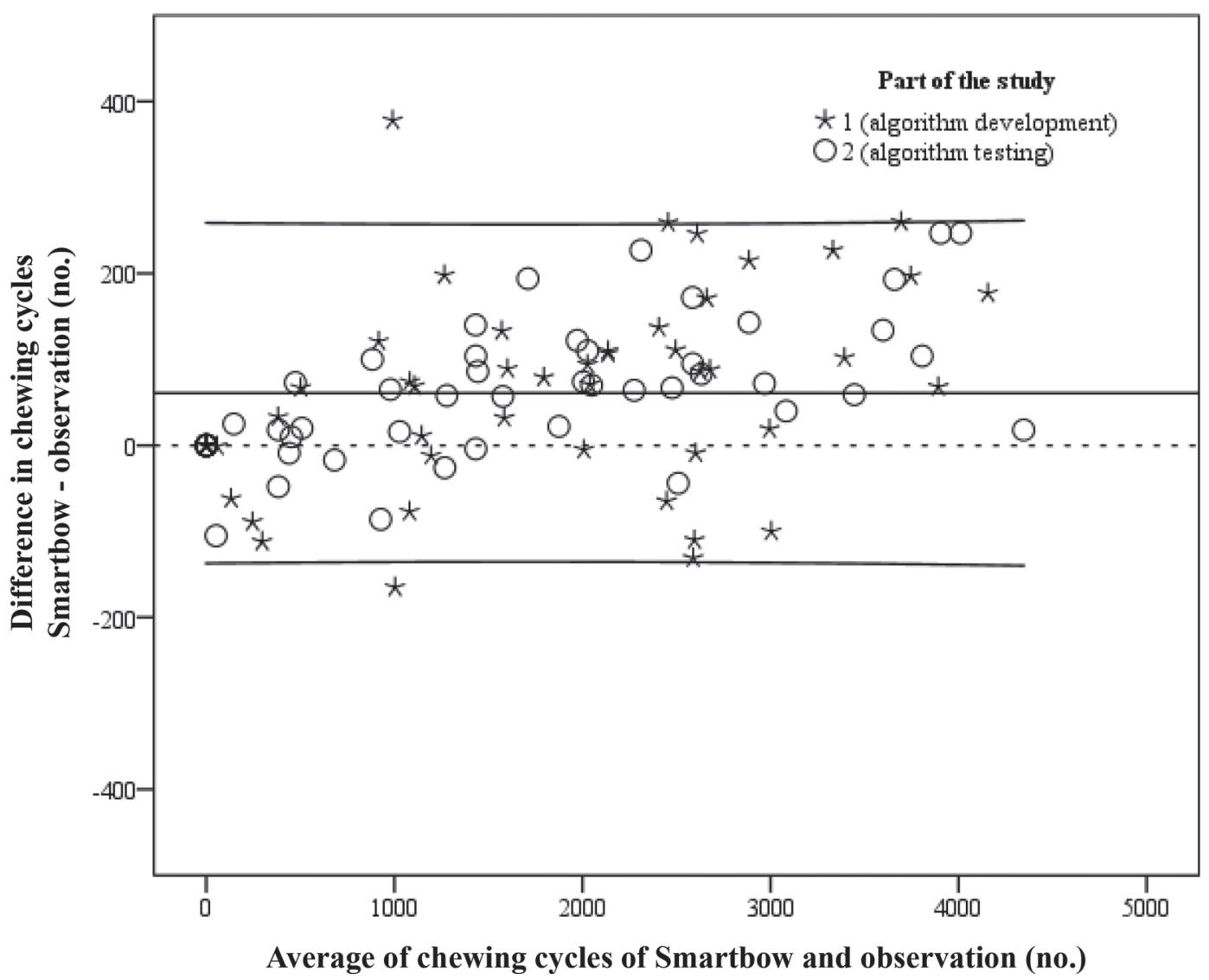

Figure 4. Differences between chewing cycles (no.) detected by Smartbow (Smartbow GmbH, Weibern, Austria) and by analyses of video recordings against their mean. Data are shown for fifty 1-h periods, each for part 1 (algorithm development) and part 2 (algorithm testing) of the study. The upper and lower solid lines illustrate the mean $\pm 2 \mathrm{SD}$, and the solid line in the middle shows the mean. The dotted line indicates zero.

direct and video observation results from 2 observers were compared and video sequences were analyzed a second time by the same observer. Direct observation results were compared with the results of video analyses to test the similarity of both methods in monitoring the rumination activity. In this study, a high agreement was determined by comparison of (human vs. human) direct and video observations. The comparison of direct visual observations, as well as the comparison of video observations resulted in a high agreement. Previous studies reported similar correlation coefficients of $\mathrm{r}>0.98$ when rumination time was scored by direct (Schirmann et al., 2009; Goldhawk et al., 2013; Ambriz-Vilchis et al., 2015) or by video observations (Goldhawk et al., 2013; Ambriz-Vilchis et al., 2015). A high agreement was also determined for comparison of video sequences analyzed a second time by the same observer. Although it can be discussed whether more observers should have re-analyzed video sequences to demonstrate the variance of intra-observer reliability, this intra-observer reliability is in agreement with results of previous stud- ies by Ambriz-Vilchis et al. (2015) and by Goldhawk et al. (2013), reporting correlations of $\mathrm{r}=0.99(P<$ 0.01 ). The duration of rumination and the number of chewing cycles determined by direct visual observation and video observation of the same observer were highly correlated. A similar correlation of $\mathrm{r}=0.97(P=0.001)$ was determined in a previous study (Goldhawk et al., 2013). These results indicate that the analysis of video recordings is an appropriate method to assess rumination activity, compared with direct visual observation.

To our knowledge, this is the first study evaluating the Smartbow system with regard to rumination time, number of chewing cycles, as well as the number of rumination bouts. A previous study by Borchers et al. (2016) evaluated rumination time with this system but did not investigate the agreement on chewing cycles or rumination bouts.

For both parts of the study (i.e., algorithm development and algorithm testing), rumination times recorded by video observation were highly correlated with those detected by Smartbow (Table 4). The manufacturer de- 
veloped their algorithms on the basis of the rumination data of the first part of the study, but the results of the accelerometer showed a similar high agreement in part 2, compared with the data of video observations. Strictly speaking, only the data of part 2 should be regarded for the evaluation of the Smartbow system. Although the results of the 2 parts differed marginally, the algorithm could have produced better results during part 1 . In most of the 1-h periods, the ear tag recorded an average rumination time that was slightly lower than the visual observed rumination time (mean difference $=-1.1 \%$ ). There was only one 1 -h period where Smartbow markedly overestimated the rumination time $(+592 \mathrm{~s})$. On second inspection of this video sequence, a failure of the observer could be ruled out. Hence, we suppose that this was an interpretation error by the Smartbow system, as the affected cow showed high activity by intensively licking on a mineral block in this period. In this video sequence, the cow showed rumination activity, but it seems that the algorithm did not recognize the end of the rumination bout as the cow switched to an activity with similar motion patterns (licking) immediately after swallowing the last bolus. Although this was the only video period where the system obviously confused a different activity for rumination activity, single measuring errors due to related activities may occur and should be evaluated in further studies.

Borchers et al. (2016) revealed a slightly lower correlation $(\mathrm{r}=0.97, P<0.01)$ between visual observed rumination time with the outcomes of the Smartbow system. However, studies are not directly comparable, as different cows in a divergent environment (e.g., housing conditions, ration composition) were used. Additionally, Borchers et al. (2016) used ear tags based on a $1-\mathrm{Hz}$ technology, whereas in this study we used $10-\mathrm{Hz}$ sensors. Capturing accelerometer data once per second (i.e., $1 \mathrm{~Hz}$ ) might miss events that are shorter than $1 \mathrm{~s}$ (e.g., single jaw movements). Hence, sensors based on $10 \mathrm{~Hz}$ provide a higher resolution per second which might have an effect on the accuracy of the detection of specific events.

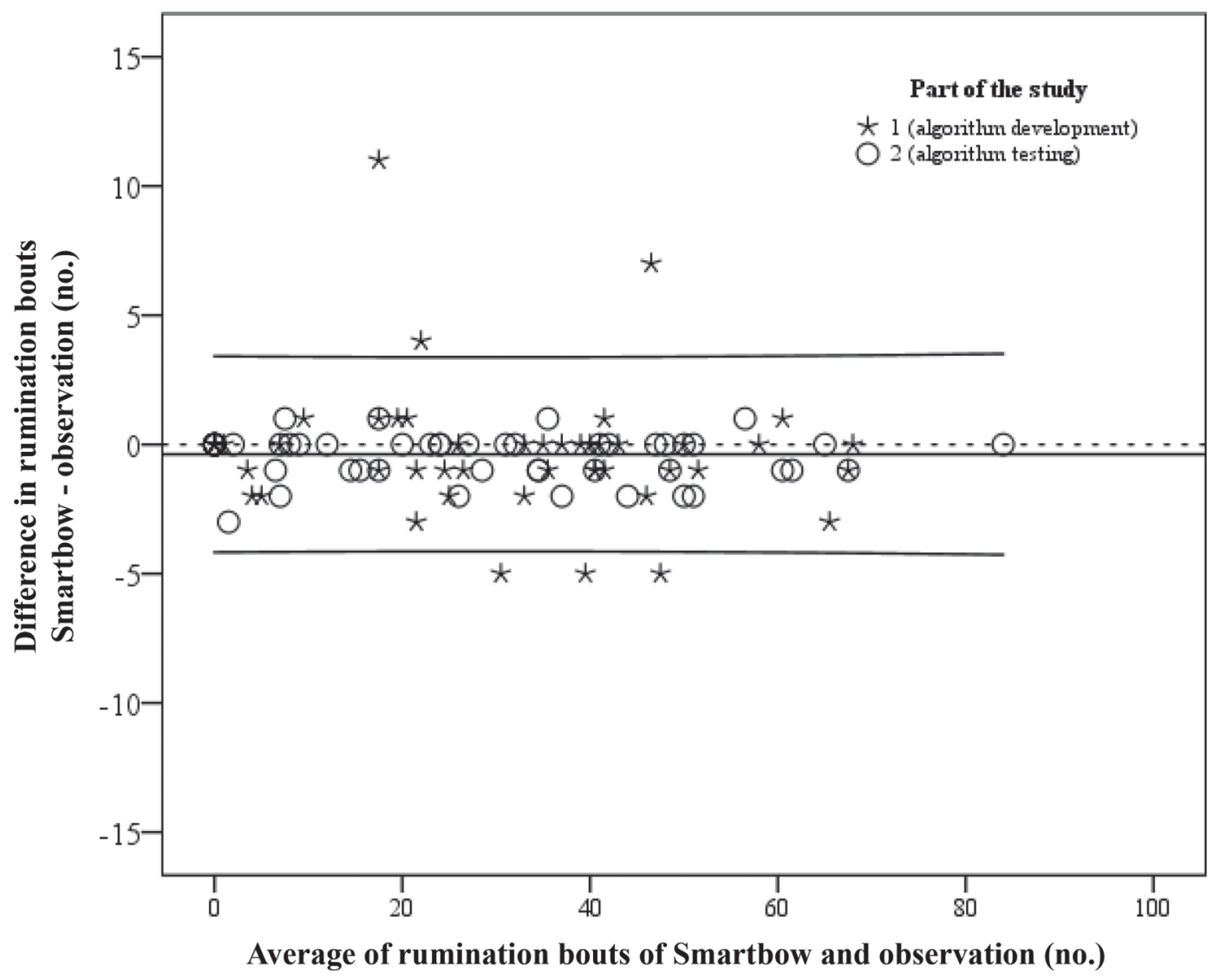

Figure 5. Differences between rumination bouts (no.) detected by Smartbow (Smartbow GmbH, Weibern, Austria) and by analyses of video recordings against their mean. Data are shown for fifty 1-h periods, each for part 1 (algorithm development) and part 2 (algorithm testing) of the study. The upper and lower solid lines illustrate the mean $\pm 2 \mathrm{SD}$, and the solid line in the middle shows the mean. The dotted line indicates zero. 


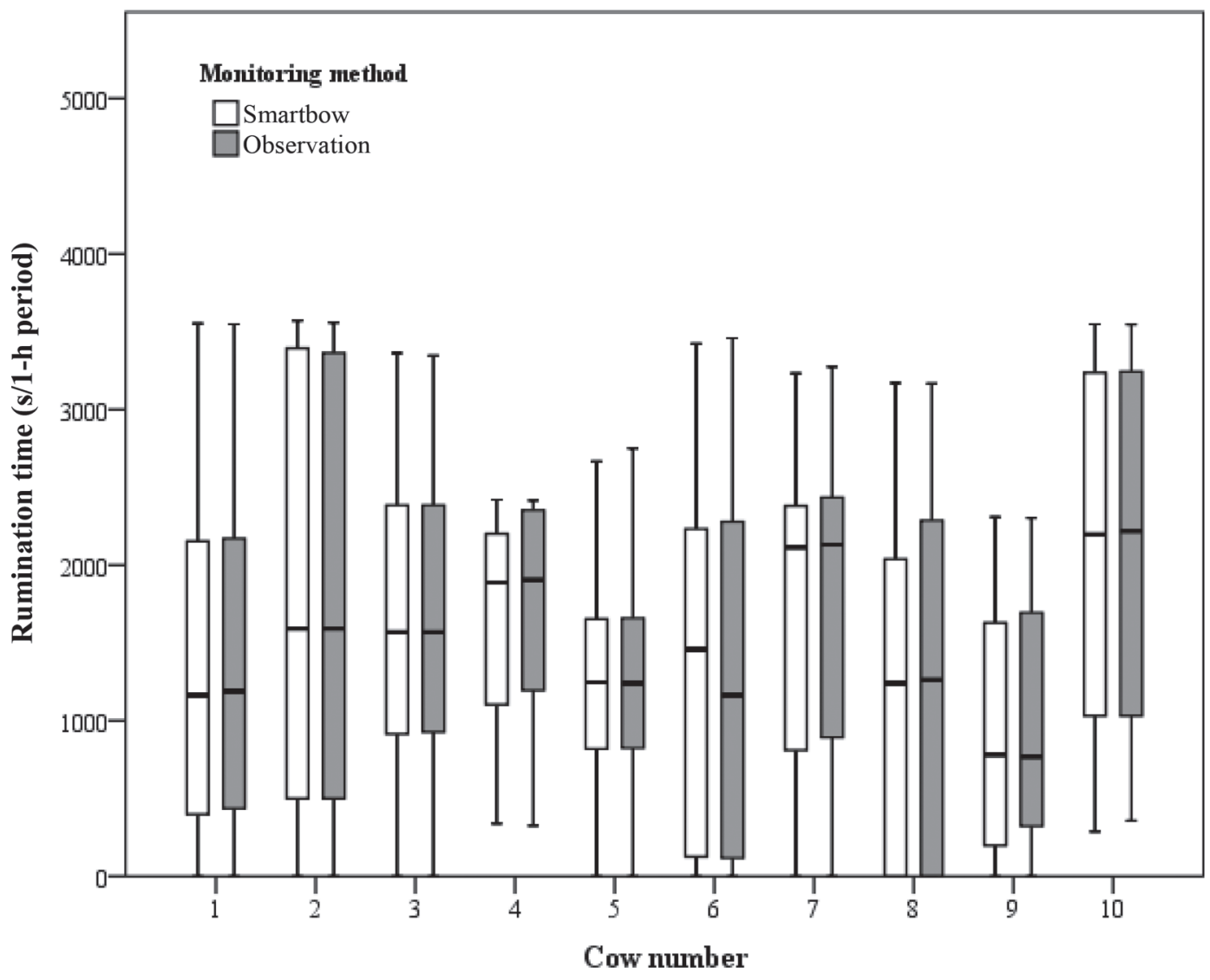

Figure 6. Boxplots of the rumination time (s) per 1-h period (10 video sequences per cow) presented separately for each cow. The heavy black line inside each box marks the median (50th percentile); lower and upper hinges mark the 25th and 75th percentiles. Whiskers end at the smallest and largest statistical values that are not outliers. Smartbow (Smartbow GmbH, Weibern, Austria).

For a different ear-attached system (SensOor, Agis Automatisering BV, Harmelen, the Netherlands), lower correlations of $\mathrm{r}=0.93$ were reported (Bikker et al., 2014; Borchers et al., 2016). Using 15 cows, Bikker et al. (2014) reported a mean \pm standard deviation visual observed rumination time of $42.1 \pm 6.9 \%$ of the total observation time. Within the same timeframe SensOor detected a rumination time of $42.6 \pm 6.8 \%$ of the total registration time. Additional studies, investigating rumination-measuring systems (Qwes-HR, Lely Ltd., St. Neots, UK) based on differing technologies are those of Ambriz-Vilchis et al. (2015), who found a lower correlation between observed rumination time and measurements of the recorded mastication sounds $(\mathrm{r}=0.81, P$ $<0.001)$. A study that evaluated a similar technology (Hi-Tag, SCR Engineers Ltd.) reported a slightly lower correlation $(\mathrm{r}=0.93, P<0.001)$ than in this study, for comparison of visual observed rumination time with automated measurements of the system (Schirmann et al., 2009). The Hi-Tag system was tested in beef cattle by Goldhawk et al. (2013), who detected a low correlation for rumination time $(\mathrm{r}=0.41, P<0.001)$.
Automatically detected rumination time exceeded the visual observed rumination time by $9.8 \pm 18.7$ (mean $\pm \mathrm{SD}$ ) min per 2-h observation periods, on average. A further study evaluating the Hi-Tag system to detect rumination time in youngstock of different age reported correlations ranging from $\mathrm{r}=0.47$ to 0.88 (Burfeind et al., 2011).

Besides rumination time, the number of chewing cycles recorded by video observations was highly correlated with the number of chewing cycles recorded by Smartbow. However, in comparison with the results of video observations Smartbow slightly overestimated the number of chewing cycles in nearly every cow. In absolute numbers, chewing cycles per bolus were overestimated by approximately 2 chews, on average. But, from a practical and clinical perspective, this deviation is considered negligible.

Rumination bouts were well detected by Smartbow, as indicated by the high correlation coefficient and the agreement between the automated measurements and the results of video observations (Table 4, Figure 5). Although the paired $t$-test showed significant differ- 
ences for some of the comparisons, the practical effect is regarded as low.

In summary, based on the determined correlation coefficients along with the specific Bland-Altman plots, the agreement between the Smartbow system and visual observations was excellent for detecting rumination time, chewing cycles, and rumination bouts. An early and reliable detection of changes of rumination activity is considered useful for herd health monitoring, in particular animal nutrition. However, further research has to be done on implementing rumination data into herd management decisions under various field conditions in indoor- and outdoor-housed cattle. As the 3 measures of the Smartbow system-rumination time, number of chewing cycles, and rumination bouts - were highly correlated, it should be evaluated if measuring only one of these parameters is sufficient for practical purposes.

Additionally, further studies may analyze the effect of changing the feeding composition as well as of diseases on the rumination parameter predicted by Smartbow.
Based on reported observations that the physical activity of cows increases during estrus (Jónsson et al., 2011) and decreases before parturition (Titler et al., 2015), this feature offered by the Smartbow system could also be useful for herd management decisions, especially in combination with rumination data.

\section{CONCLUSIONS}

In this study, the Smartbow system was eligible in detecting rumination time, chewing cycles, as well as rumination bouts in indoor-housed dairy cows. The determined correlation coefficients as well as the agreement between the Smartbow system and the results of video analyses were excellent. From a practical and clinical point of view, the detected differences between visual observations and the Smartbow systems during algorithm testing in rumination time $(-1.2 \%)$, chewing cycles $(+3.7 \%)$, and rumination bouts $(-1.8 \%)$ are negligible. However, further research is necessary to

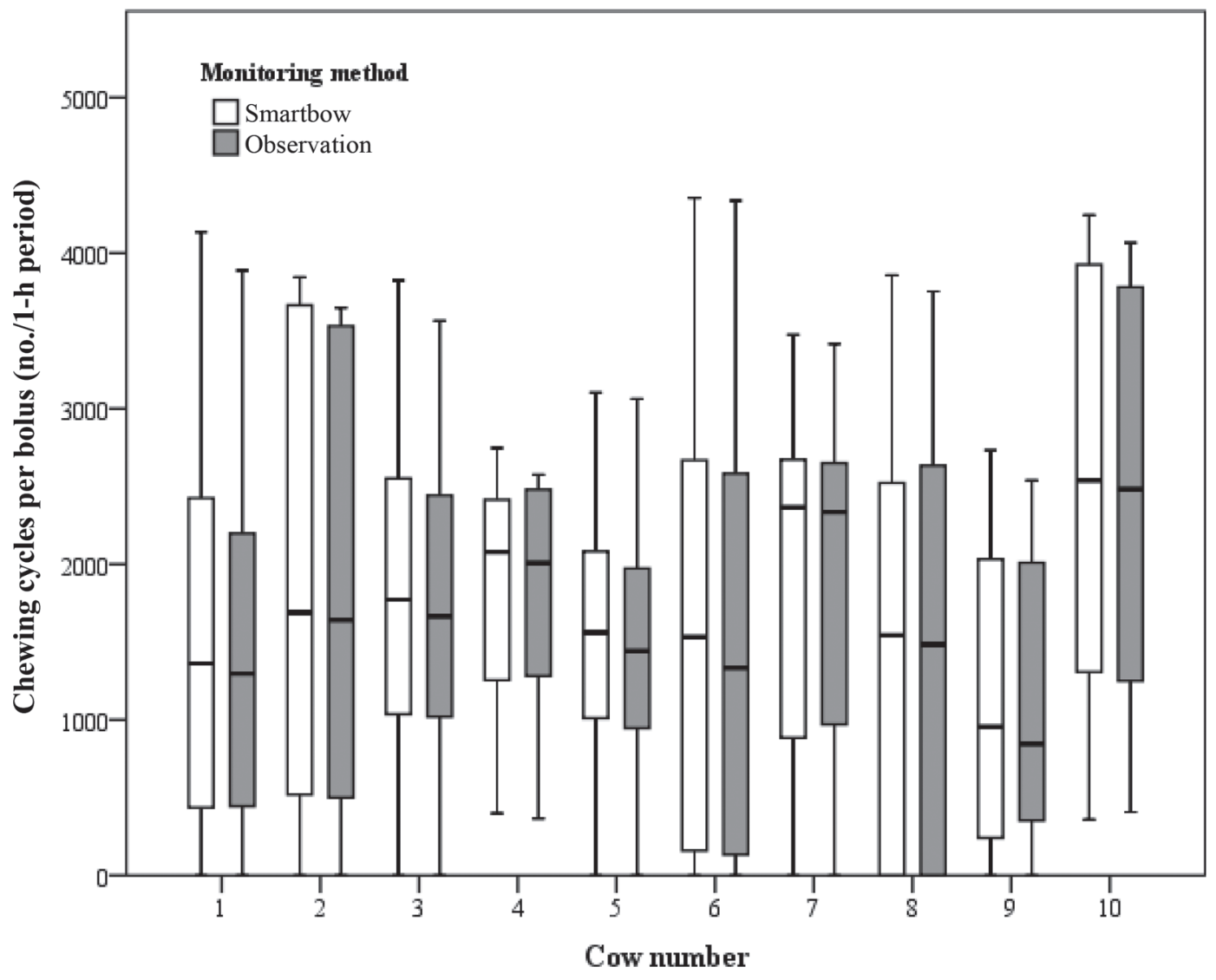

Figure 7. Boxplots of the chewing cycles (no.) per 1-h period (10 video sequences per cow) presented separately for each cow. The heavy black line inside each box marks the median (50th percentile); lower and upper hinges mark the 25th and 75th percentiles. Whiskers end at the smallest and largest statistical values that are not outliers. Smartbow (Smartbow GmbH, Weibern, Austria). 


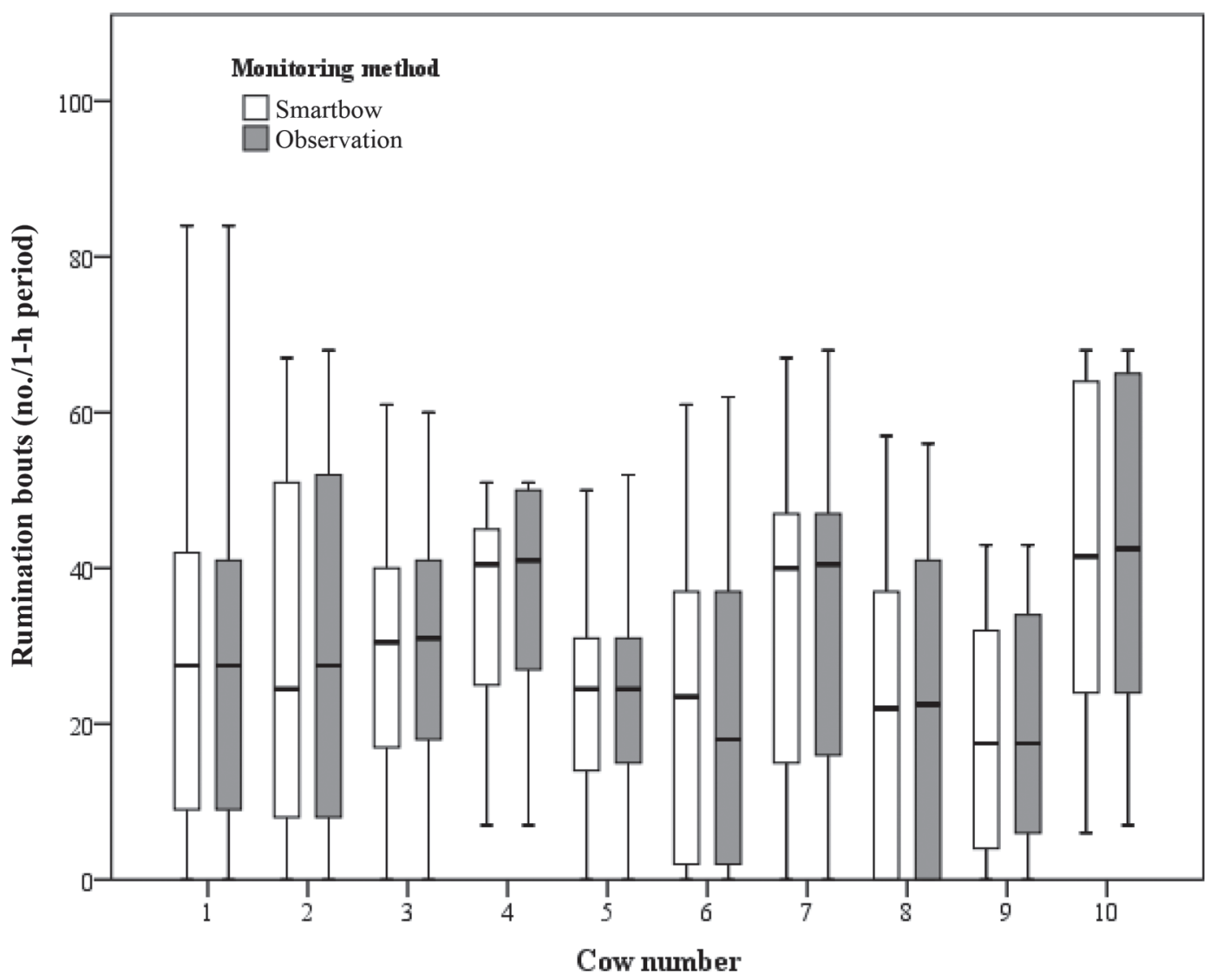

Figure 8. Boxplots of the rumination bouts (no.) per 1-h period (10 video sequences per cow) presented separately for each cow. The heavy black line inside each box marks the median (50th percentile); lower and upper hinges mark the 25th and 75th percentiles. Whiskers end at the smallest and largest statistical values that are not outliers. Smartbow (Smartbow GmbH, Weibern, Austria).

Table 3. Intra- and inter-observer reliability as well as the association between direct visual and video observations: Pearson correlation coefficient $(\mathrm{r})$, averages (mean $\pm \mathrm{SD})$, differences (mean $\pm \mathrm{SD}$ ), and the results of a paired $t$-test for rumination time $(\mathrm{s} / \mathrm{h})$ and chewing cycles (no./h)

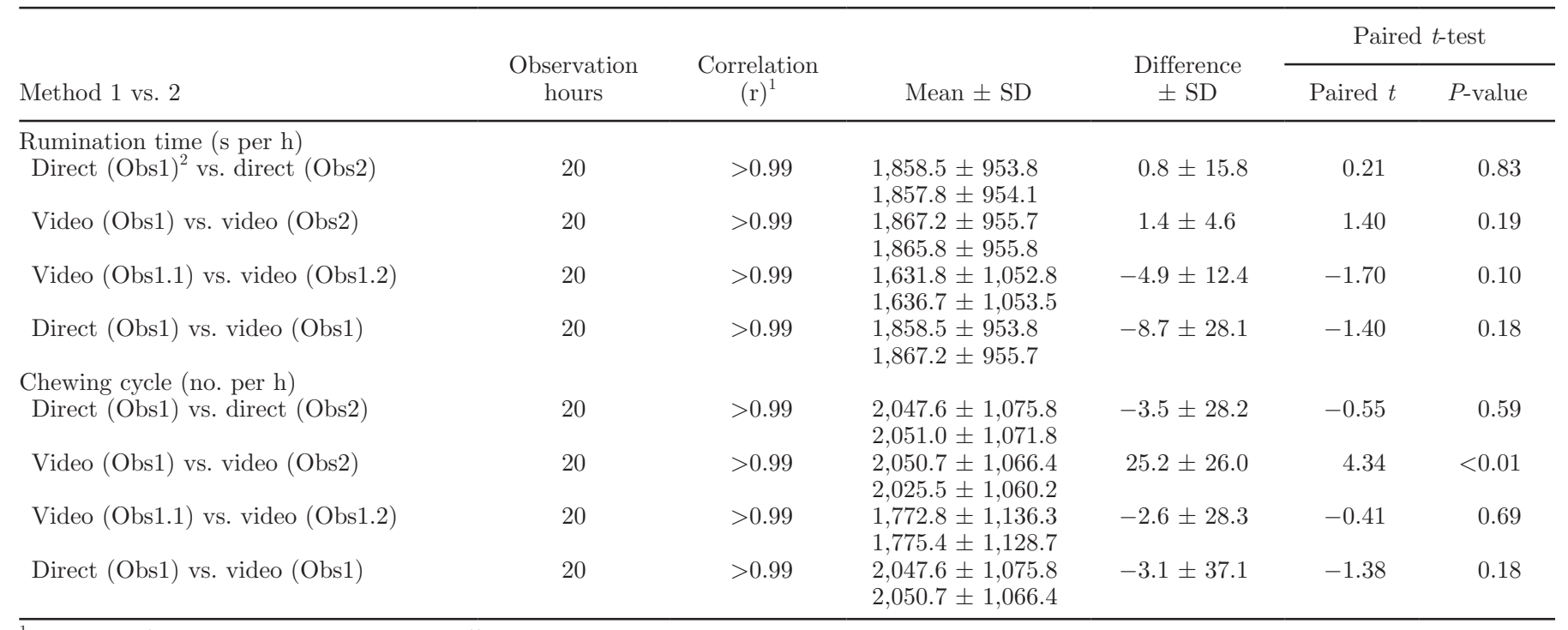

${ }^{1} P<0.001$ for all Pearson correlation coefficients.

${ }^{2}$ Obs1 or Obs2 = observer 1 or 2; Obs1.1/1.2 = first versus repeated observation of observer 1. 
test the system under various field conditions and to evaluate the benefit of incorporating rumination data into herd management decisions.

\section{ACKNOWLEDGMENTS}

We thank the staff from the Teaching and Research Farm Kremesberg of the University of Veterinary Medicine, Vienna (Austria) for their technical assistance. We thank the Austrian Association for Buiatrics (ÖBG) for funding this study, in part. Stefan Reiter submitted this study as diploma thesis at the University of Veterinary Medicine, Vienna (Austria).

\section{REFERENCES}

Ambriz-Vilchis, V., N. S. Jessop, R. H. Fawcett, D. J. Shaw, and A. I. Macrae. 2015. Comparison of rumination activity measured using rumination collars against direct visual observations and analysis of video recordings of dairy cows in commercial farm environments. J. Dairy Sci. 98:1750-1758.

Beauchemin, K. A. 1991. Ingestion and mastication of feed by dairy cattle. Vet. Clin. North Am. Food Anim. Pract. 7:439-463.

Beauchemin, K. A., S. Zelin, D. Genner, and J. G. Buchanan-Smith. 1989. An automatic system for quantification of eating and ruminating activities of dairy cattle housed in stalls. J. Dairy Sci. $72: 2746-2759$

Bikker, J. P., H. van Laar, P. Rump, J. Doorenbos, K. van Meurs, G. M. Griffioen, and J. Dijkstra. 2014. Technical note: Evaluation of an ear-attached movement sensor to record cow feeding behavior and activity. J. Dairy Sci. 97:2974-2979.

Bland, J. M., and D. G. Altman. 1986. Statistical methods for assessing agreement between two methods of clinical measurement. Lancet 1:307-310.

Borchers, M. R., Y. M. Chang, I. C. Tsai, B. A. Wadsworth, and J. M. Bewley. 2016. A validation of technologies monitoring dairy cow feeding, ruminating, and lying behaviors. J. Dairy Sci. 99:74587466.

Burfeind, O., K. Schirmann, M. A. von Keyserlingk, D. M. Veira, D. M. Weary, and W. Heuwieser. 2011. Evaluation of a system for monitoring rumination in heifers and calves. J. Dairy Sci. 94:426430.

Clark, C. E., N. A. Lyons, L. Millapan, S. Talukder, G. M. Cronin, K. L. Kerrisk, and S. C. Garcia. 2015. Rumination and activity levels as predictors of calving for dairy cows. Animal 9:691-695.

Focant, M., F. Gallouin, and M. Leclercq. 1979. Volatile fatty acids and rumination in the goat. Ann. Rech. Vet. 10:226-228.

Gáspárdy, A., G. Efrat, A. Bajcsy, and S. Fekete. 2014. Electronic monitoring of rumination activity as an indicator of health status and production traits in high-yielding dairy cows. Acta Vet. Hung. $62: 452-462$.

Goldhawk, C., K. Schwartzkopf-Genswein, and K. A. Beauchemin. 2013. Technical note: Validation of rumination collars for beef cattle. J. Anim. Sci. 91:2858-2862.

Herskin, M. S., L. Munksgaard, and J. Ladewig. 2004. Effects of acute stressors on nociception, adrenocortical responses and behavior of dairy cows. Physiol. Behav. 83:411-420.

Jónsson, R., M. Blanke, N. K. Poulsen, F. Caponetti, and S. Højsgaard. 2011. Oestrus detection in dairy cows from activity and lying data using on-line individual models. Comput. Electron. Agric. 76:6-15.

Kononoff, P. J., H. A. Lehman, and A. J. Heinrichs. 2002. Technical Note - A comparison of methods used to measure eating and ruminating activity in confined dairy cattle. J. Dairy Sci. 85:1801-1803.

Liboreiro, D. N., K. S. Machado, P. R. B. Silva, M. M. Maturana, T. K. Nishimura, A. P. Brandão, M. I. Endres, and R. C. Chebel. 
2015. Characterization of peripartum rumination and activity of cows diagnosed with metabolic and uterine diseases. J. Dairy Sci. 98:6812-6827.

Metz, J. H. M. 1975. Time patterns of feeding and rumination in domestic cattle. PhD Thesis. Landbouwhogeschool te Wageningen, Wageningen, the Netherlands.

Pahl, C., E. Hartung, A. Grothmann, K. Mahlkow-Nerge, and A. Haeussermann. 2014. Rumination activity of dairy cows in the 24 hours before and after calving. J. Dairy Sci. 97:6935-6941.

Reith, S., and S. Hoy. 2012. Relationship between daily rumination time and estrus of dairy cows. J. Dairy Sci. 95:6416-6420.

Schirmann, K., M. A. von Keyserlingk, D. M. Weary, D. M. Veira, and W. Heuwieser. 2009. Technical note: Validation of a system for monitoring rumination in dairy cows. J. Dairy Sci. 92:6052-6055.

Stangaferro, M. L., R. Wijma, L. S. Caixeta, M. A. Al-Abri, and J. O. Giordano. 2016a. Use of rumination and activity monitoring for the identification of dairy cows with health disorders: Part I. Metabolic and digestive disorders. J. Dairy Sci. 99:7395-7410.

Stangaferro, M. L., R. Wijma, L. S. Caixeta, M. A. Al-Abri, and J. O. Giordano. 2016b. Use of rumination and activity monitoring for the identification of dairy cows with health disorders: Part II. Mastitis. J. Dairy Sci. 99:7411-7421.
Stangaferro, M. L., R. Wijma, L. S. Caixeta, M. A. Al-Abri, and J. O. Giordano. 2016c. Use of rumination and activity monitoring for the identification of dairy cows with health disorders: Part III. Metritis. J. Dairy Sci. 99:7422-7433.

Suzuki, T., Y. Kamiya, M. Tanaka, I. Hattori, T. Sakaigaichi, T. Terauchi, I. Nonaka, and F. Terada. 2014. Effect of fiber content of roughage on energy cost of eating and rumination in Holstein cows. Anim. Feed Sci. Technol. 196:42-49.

Titler, M., M. G. Maquivar, S. Bas, P. J. Rajala-Schultz, E. Gordon, K. McCullough, P. Federico, and G. M. Schuenemann. 2015. Prediction of parturition in Holstein dairy cattle using electronic data loggers. J. Dairy Sci. 98:5304-5312.

Umemura, K., T. Wanaka, and T. Ueno. 2009. Technical note: Estimation of feed intake while grazing using a wireless system requiring no halter. J. Dairy Sci. 92:996-1000.

Welch, J. G. 1982. Rumination, particle size and passage from the rumen. J. Anim. Sci. 54:885-894.

Wolfger, B., B. W. Jones, K. Orsel, and J. M. Bewley. 2017. Technical note: Evaluation of an ear-attached real-time location-monitoring system. J. Dairy Sci. 100:2219-2224. 